\title{
A RELAÇÃO ENTRE METAPSICOLOGIA E CIÊNCIA NATURAL: UM DEBATE À LUZ DA FILOSOFIA DE HEIDEGGER
}

\author{
Jilvania de Jesus Barbosa 1; Caroline Vasconcelos Ribeiro 2
}

1: Bolsista PIBIC/FAPESB, Graduanda em Psicologia, Universidade Estadual de Feira de Santana, e-mail: vaniabarbosa.js@gmail.com

2: Orientadora, Departamento de Ciências Humanas e Filosofia, Universidade Estadual de Feira de Santana, e-mail: carolinevasconcelos@ hotmail.com

PALAVRAS-CHAVE: Freud; Heidegger; Metapsicologia.

\section{INTRODUÇÃO}

O presente manuscrito objetiva apresentar, de forma breve, os resultados derivados de uma pesquisa que teve a tarefa de explicitar a veemente crítica de Heidegger dirigida à metapsicologia freudiana. Intitulada "A relação entre metapsicologia e ciência natural: um debate à luz da filosofia de Heidegger", a referida pesquisa contou com o apoio da FAPESB. Examinamos a teoria metapsicológica a partir das considerações de Heidegger em sua obra Seminários de Zollikon. Na obra citada, Heidegger (2001) faz severas críticas ao naturalismo presente, especialmente, na metapsicologia de Freud. Na perspectiva heideggeriana, esta parte especulativa da psicanálise foi construída em um solo epistemológico marcado pela filosofia neokantiana e pelas ciências naturais. (HEIDEGGER, 2001, p. 222). Entretanto, na obra Análise Terminável e interminável (1996a), Freud qualifica a metapsicologia como uma espécie de feiticeira, como um recurso teórico que equivaleria a uma fantasia. Nos questionamos como uma teoria que postula conceitos como "inconsciente" e "pulsão" pode ser vinculada aos métodos das ciências naturais, que certamente trabalham com noções precisas e verificáveis Em nossa comunicação almejamos examinar os seguintes questionamentos levantados ao longo da pesquisa: como os procedimentos das ciências da natureza podem ser compatíveis com uma teoria especulativa, que postula conceitos nebulosos e se assume em semelhança a um fantasiar? Heidegger teria razão ao apontar uma herança científico-natural na metapsicologia se o próprio Freud diz que esta teoria é uma espécie de feitiçaria?

\section{MATERIAL, MÉTODOS OU METODOLOGIA (ou equivalente)}

O plano de trabalho ao qual está atrelado este resumo baseia-se em uma pesquisa bibliográfica. Nosso primeiro passo metodológico consistiu no estudo do conceito de Metapsicologia, para assim termos propriedade de fazer a correlação com a crítica de Heidegger em relação a esta teoria freudiana. Investigamos obras que Freud tematiza a natureza e a evolução da teoria e de conceitos metapsicológicos: Análise terminável $e$ interminável (1996a), A pulsão e seus destinos (1996b), Ansiedade e vida pulsional (1996c), Novas conferências introdutórias sobre psicanálise (1996d) Um estudo autobiográfico (1996e) Esboço de Psicanálise (1996f), Algumas lições elementares de psicanálise (1996g) e Por que a guerra? (1996h). Com o intuito de compreender como é formado e quais são as características de um constructo metapsicológico, analisamos os seguintes artigos de metapsicologia: O Inconsciente (2006a), e O Recalque (2006b). O segundo passo consistiu numa análise, pormenorizada, da obra Seminários de Zollikon (2001). Do filósofo também analisamos passagens de Ser e Tempo (2004), Cartas sobre o humanismo (2009) e Que é 
metafísica? (1991). Nosso passo seguinte baseou-se em um exame detalhado de obras de comentadores que pesquisam a metapsicologia freudiana a partir de um olhar filosófico. Utilizamos como referência obras de Paul-Laurent Assoun, quais sejam: Introdução à epistemologia freudiana (1983), Metapsicologia freudiana: uma introdução (1996), Freud a filosofia e os filósofos (1978) e A metapsicologia (2002). Trabalhamos na leitura de textos de Zeljko Loparic - Além do inconsciente, sobre a desconstrução da psicanálise (2001), A máquina no homem (2005) - e de Leopoldo Fulgencio, a saber: Convocação para a fundação de uma Sociedade para Filosofia Positivista (2000), As Especulações metapsicológicas de Freud (2003), Freud e a ficção teórica do aparelho psíquico (2008a) e $O$ método especulativo em Freud (2008b). Examinamos também o livro de Luiz R. Monzani intitulado Freud: o movimento de um pensamento (1989). Recorremos, ainda, ao comentário realizado por Garcia-Roza em sua coleção sobre metapsicologia. Para análise de termos heideggerianos nos servimos do Dicionário Heidegger de Inwood (2002) e, em relação aos termos freudianos, recorreremos ao Vocabulário de Psicanálise de Laplanche e Pontalis (1992) e ao livro As palavras de Freud: Vocabulário freudiano e suas versões (2010) de Paulo C. Souza. Para análise dos pressupostos das ciências da natureza utilizamos como fonte a obra: Princípios metafísicos da ciência da natureza (1990) do filósofo Immanuel Kant.

\section{RESULTADOS E/OU DISCUSSÃO (ou análise e discussão dos resultados)}

No artigo metapsicológico A pulsão e seus destinos Freud (1996b) faz uma espécie de defesa quanto ao uso de constructos especulativos, os quais não têm fundamentação empírica. O psicanalista defende que o material especulativo é indispensável para o fazer científico. Segundo o pai da psicanálise, no artigo em comento, não se pode fazer ciência só com observação de fenômenos ou com conceitos claros e bem definidos, sendo assim, o cientista é forçado a se servir de constructos que são obscuros e abstratos, mas que têm valor para explicar fenômenos. Em Análise Terminável e Interminável (1996a, p. 238) encontramos a defesa do uso de especulações como fonte primordial para explicar os fatos da vida psíquica. Freud considera que não se chega a nenhum resultado observável sem uma teorização deste tipo. Conceitos sem realidade empírica como "inconsciente", "pulsão" "aparelho psíquico" funcionam como construções auxiliares frutíferas para a apreensão de fenômenos empíricos. Para o pai da psicanálise "Sem especulação e teorização metapsicológica - quase disse fantasiar - não daremos outro passo à frente." (FREUD, 1996a, p. 238). No escrito supracitado Freud faz alusão à obra Fausto de Goethe, quando menciona o trecho: "Temos de chamar a feiticeira em nosso auxílio". A feiticeira é associada à metapsicologia.

No texto Ansiedade e vida pulsional Freud (1996c, p.98) afirma: "A teoria das pulsões é, por assim dizer, nossa mitologia." Em nossa investigação, notamos que estas referências à imprecisão, à natureza convencional e à mitologia revelam a influência de uma linguagem que tem em Kant e em neokantianos como Ernst Mach seu aporte teórico. Mach foi um físico vienense que, desde o fim do século XIX, levantou a bandeira acerca do uso de convenções de valor heurístico na apreensão dos fenômenos observáveis. Segundo Fulgencio (2003, p. 155) “(...) os conceitos e modelos especulativos, as representações de Mach são como na metapsicologia freudiana, superestruturas especulativas das teorias científicas". Mach defendeu claramente o uso de representações auxiliares no ordenamento e na explicabilidade de relações empíricas. Para Assoun (1983), não resta dúvida que é na obra machiana Conhecimento e erro que Freud vai buscar uma parte considerável do seu pequeno capital epistemológico. Nesta obra Mach relata que o uso de especulações - ou representações fantasias - nas ciências se assemelha a uma espécie de feitiçaria que deve ser respeitada. $\mathrm{O}$ físico vienense argumenta que, no início do desenvolvimento da física, teríamos uma mitologia da natureza cujos elementos aproximavam-se eram terra, fogo, ar e água. Tal mitologia da natureza teria sido substituída inicialmente por uma "mitologia das substâncias e 
das forças" e na fase mais madura por uma "mitologia dinâmica". Ao longo de nossa investigação constatamos que, ao associar a metapsicologia e os conceitos metapsicológicos à feitiçaria e à mitologia, Freud está se servindo de uma terminologia avalizada pelo físico neokantiano Ernst Mach.

Ao examinar os pressupostos metodológicos que subjazem ao legado freudiano, Heidegger declara que "a metapsicologia de Freud é a transferência da filosofia neokantiana para o homem. De um lado ele tem as ciências naturais e de outro a teoria kantiana da objetividade." (2001, p. 222). Ao examinarmos esta assertiva heideggeriana constatamos que tal herança consiste em tornar lícito o uso de ideias abstratas para conduzir o entendimento na ordenação e apreensão de fenômenos empíricos. Tais ideias referem-se aos conceitos metapsicológicos

\section{CONCLUSÃO OU CONSIDERAÇÕES FINAIS}

Ao elaborar sua metapsicologia Freud, segundo a perspectiva heideggeriana, teria transferido a filosofia neokantiana e os procedimentos científico-naturais para o entendimento de fenômenos humanos. A partir do exame bibliográfico que fizemos em nosso itinerário de pesquisa pudemos concluir que, ao formular seus imprecisos conceitos metapsicológicos, Freud não rompe com a maneira de fazer ciência de sua época. A afinidade com o campo científico-natural de matriz neokantiana, apontada por Heidegger, não se constata apenas nos trabalhos de sua formação inicial, mas em formulações futuras. Não só o conceito metapsicológico de pulsão é tomado de empréstimo das ciências naturais, mas as analogias com os aparelhos ópticos também são. $\mathrm{O}$ recurso analógico é utilizado por Freud não de forma aleatória, mas como um recurso metodológico capaz de tornar inteligível o funcionamento psíquico do homem. Ao lermos suas obras notamos o quão corriqueiro é a presença de analogias e metáforas. Estas não impugnam o cientificismo natural da psicanálise, ao contrário, são avalizadas pelo modelo cientifico de matriz neokantiana. No fim do séc. XIX e começo do séc. XX o uso de analogias e especulações é visto como um lícito instrumento heurístico para as ciências. Desta forma, ao formular conceitos como pulsão, aparelho psíquico, ou seja, ao formular sua metapsicologia Freud não rompeu com o padrão de ciência de sua época. Cabe ressaltar que é justamente por utilizar explicações causais, naturalizar o psiquismo e compará-lo a aparelhos, que Heidegger lança sua crítica à psicanálise freudiana. Em nossa discussão notamos que essa crítica de Heidegger encontra ressonância na obra de epistemólogos da psicanálise como Assoun, Fulgencio e Loparic.

\section{REFERÊNCIAS:}

ASSOUN, P-L. Introdução à epistemologia freudiana. Tradução: Hilton Japiassu. Rio de Janeiro: imago, 1983.

ASSOUN, P-L. Metapsicologia freudiana: uma introdução. Rio de Janeiro: Jorge Zahar, 1996.

ASSOUN, P-L. Freud a Filosofia e os filósofos. Tradução de Hilton Japiassu. Rio de Janeiro: F. Alves, 1978.

ASSOUN, P-L. A Metapsicologia. Lisboa: CLIMEPSI, 2002.

FREUD, S. "Análise terminável e interminável". in: Obras psicológicas completas de Sigmund Freud. Rio de Janeiro: Imago Editora, 1996a Vol. XXIII.

FREUD, S. "A pulsão e seus destinos". In: Edição Standard brasileira das obras completas de Sigmund Freud. Rio de Janeiro: Imago Editora, 1996b. Vol. XIV.

FREUD, S. "Ansiedade e vida pulsional". In: Edição Standard brasileira das obras completas de Sigmund Freud. Rio de Janeiro: Imago Editora, 1996c. Vol. XXII. 
FREUD, S. "Novas conferências introdutórias sobre psicanálise" In: Edição Standart brasileira das obras completas de Sigmund Freud, Rio de Janeiro: Imago Editora, 1996d, Vol. XXII.

FREUD, S. "Um estudo autobiográfico". In: Edição Standard brasileira das obras completas de Sigmund Freud. Rio de Janeiro: Imago Editora, 1996e. Vol. XX.

FREUD, S. "Esboço de psicanálise". In: Edição Standard brasileira das obras completas de Sigmund Freud. Rio de Janeiro: Imago Editora, 1996f. Vol. XXIII.

FREUD, S. "Algumas lições elementares de psicanálise". in: Obras psicológicas completas de Sigmund Freud. Rio de Janeiro: Imago Editora,1996g Vol. XXIII

FREUD, S. "Por que a guerra?". In: Obras psicológicas completas de Sigmund Freud. Rio de Janeiro: Imago Editora, 1996h. Vol. XXII.

FREUD, S. "O Inconsciente". In: Obras psicológicas completas de Sigmund Freud. Tradução de Luiz Alberto Hans. - Rio de Janeiro: Imago Editora. Vol. II, 2006 .

FREUD, S. "O Recalque". In: Obras psicológicas completas de Sigmund Freud. Tradução de Luiz Alberto Hanns. - Rio de Janeiro: Imago Editora. Vol. II, 2006 b.

FULGENCIO, L. "Convocação para a fundação de uma 'Sociedade para a Filosofia Positivista"". Revista: Natureza humana, vol.2, n.2, 2000.

FULGENCIO, L. "As Especulações metapsicológicas de Freud". In: Natureza Humana Revista Internacional de Filosofia e Psicanálise. São Paulo: EDUC, vol. 3 n. 1, 2003.

FULGENCIO, L. "Freud e a ficção teórica do aparelho psíquico". In: AIRES, S.; Ribeiro, C. (org). Ensaios de Filosofia e Psicanálise. Campinas, SP: Mercado de Letras, 2008a.

FULGENCIO, L. O método especulativo em Freud. São Paulo:EDUC, 2008b.

GARCIA-ROZA, L. "Artigos de metapsicologia: narcisismo, pulsão, recalque, inconsciente". In: Introdução à metapsicologia freudiana, v. 3, $7^{\text {a }}$ ed. Rio de Janeiro: Jorge Zahar Ed., 1995.

HEIDEGGER, M. Seminários de Zollikon. Tradução de Gabriela Arnhold, Maria de Fátima de Almeida Prado. - São Paulo: EDUC; Petrópolis, RJ: Vozes, 2001.

HEIDEGGER, M. Ser e Tempo. Tradução e notas de Maria Sá Cavalcante Shuback. Petrópolis: Vozes, 2004.

HEIDEGGER, M. "Que é metafísica?" In: Conferências e escritos filosóficos. (Coleção Os pensadores) Tradução e notas de Ernildo Stein. São Paulo. Abril Cultural, 1991.

HEIDEGGER, M. Carta sobre o humanismo. Introdução, tradução e notas de Emmanuel Carneiro Leão. 3.ed. Rio de Janeiro: Edições Tempo Brasileiro, 2009.

INWOOD, M. "Dicionário Heidegger." Tradução de Luísa Buarque de Holanda. Rio de Janeiro: Jorge Zahar Editor, 2002.

KANT, Immanuel. Princípios metafísicos da ciência da natureza. Tradução de Artur Morão. Rio de Janeiro: Edições 70, 1990.

LAPLANCHE, J. E PONTALIS, J.B. Vocabulário da Psicanálise. Tradução: Pedro Tamen. São Paulo: Martins Fontes, 2001.

LOPARIC, Z. "Além do Inconsciente - sobre a desconstrução heideggeriana da psicanálise". In: Natureza Humana - Revista Internacional de Filosofia e Psicanálise. São Paulo: EDUC, vol. 3.n 1, 2001.

LOPARIC, Z. "A máquina no Homem". In: FULGENCIO, L. e SIMANKE, R. (org). Freud na Filosofia Brasileira. São Paulo: Escuta, 2005.

MONZANI, Luiz Roberto. "A máquina de sonhar." In: Freud: o movimento de um pensamento. 2. ed. Campinas, SP: Editora UNICAMP, 1989.

SOUZA, P. C. "As palavras de Freud: vocabulário freudiano e suas versões". São Paulo: Companhia das Letras, 2010. 